\title{
Relationship between NT-proBNP and Cardio-Renal Dysfunction in Patients with Advanced Liver Cirrhosis
}

\author{
Adriana Cavaşi ${ }^{1,2}$, Eduard Cavaşi $^{3}$, Mircea Grigorescu ${ }^{1,2}$, Adela Sitar-Tăut ${ }^{4}$
}

1) Regional Institute of

Gastroenterology and

Hepatology Prof. Dr. Octavian

Fodor;

2) 3rd Medical Clinic, Iuliu

Haţieganu University of

Medicine and Pharmacy;

3) Integrated Ambulatory

of the Clinical Hospital of

Infectious Diseases;

4) Babeş-Bolyai University,

Cluj-Napoca, Romania

Address for correspondence: Adriana Cavaşi, MD, PhD

Regional Institute of

Gastroenterology and

Hepatology

3rd Medical Clinic

19-21, Croitorilor Str

400162, Cluj-Napoca,

Romania

adriana_cavaşi@yahoo.com

\section{ABSTRACT}

Background \& Aims: ProBNP is a sensitive marker of cardiac dysfunction. We assessed the concentration of circulating NT-proBNP in patients with liver cirrhosis in various stages of the disease and its correlation with markers of cardiac and renal dysfunction and with markers of liver disease severity.

Patients and methods: A number of 88 patients with liver cirrhosis were included in the study, divided into 3 groups: group 1 - 18 control patients without ascites; group 2 - 35 non-azotemic patients with ascites; group 3 - 35 patients with hepatorenal syndrome. The cardiac dysfunction was assessed by measuring the NTproBNP serum levels and the QTc interval. The markers of renal dysfunction were the estimated glomerular filtration rates - formulas involving creatinine and serum cystatin C. The Child-Pugh score was used to assess the liver disease severity.

Results: The median NT-proBNP serum levels significantly increased in patients with advanced liver cirrhosis (group 3: $960 \mathrm{fmol} / \mathrm{ml}$ and group 2: $660 \mathrm{fmol} / \mathrm{ml}$ ) as compared to group $1(435 \mathrm{fmol} / \mathrm{ml})(\mathrm{p}<0.05)$. A significant direct correlation was found between the NT-proBNP concentration and the QTc interval $(r=0.540, p<0.001)$. The NT-proBNP levels also correlated with the Child-Pugh score $(\mathrm{r}=0.501, \mathrm{p}<0.01)$, proving the link between the cardiac dysfunction and the liver disease severity. The cardio-renal interrelation is supported by the relationship between the NT-proBNP concentration and the estimated clearances.

Conclusion: The high NT-proBNP levels in patients with advanced cirrhosis indicate the presence of cardiac dysfunction, which has a role in the pathogenesis of the hepatorenal syndrome.

Key words: liver cirrhosis - cirrhotic cardiomyopathy - proBNP - NT-proBNP - hepatorenal syndrome cardio-renal dysfunction.

Abbreviations: DP: diastolic pressure; GFR: glomerular filtration rate; HRS: hepatorenal syndrome; MAP: mean arterial pressure; NT-proBNP: N-terminal fragment of the prohormone B-type natriuretic peptide; proBNP: prohormone brain natriuretic peptide; SBP: spontaneous bacterial peritonitis; SP: systolic pressure; TIPS: tranjugular intrahepatic portosystemic shunt.

Received: 19.11.2013

Accepted: 04.02.2014

\section{INTRODUCTION}

Circulatory and cardiac dysfunction, caused by splanchnic vasodilation, was reported in patients with liver cirrhosis. The hyperdynamic circulation and the activation of potent vasoconstrictor systems may overload the heart [1-3].

Clinical and experimental studies have revealed a latent cardiac dysfunction, characterized by decreased contractile response to stress, altered diastolic relaxation, and electrophysiological anomalies - QT interval prolongation, in the absence of any organic cardiac disease. All these alterations define the cirrhotic cardiomyopathy $[4,5]$. Cirrhotic patients, due to cardiac dysfunction, have impaired prognosis and a worse outcome during infections (spontaneous bacterial peritonitis, SBP) or during invasive procedures such as surgery, TIPS implantation or hepatic transplantation [6-8].

The cardiac dysfunction is frequently latent and only becomes apparent because of overexertion. The decreased systolic function diminishes the renal blood flow and sodium excretion, leading to severe complications such as: sodium and water retention, ascites and hepatorenal syndrome (HRS) [9]. The B-type natriuretic peptide (BNP) and its prohormone 
(pro-BNP) are sensitive markers of ventricular dysfunction. Maintaining cardiac contractility is an important link in the prevention of renal dysfunction and HRS in patients with advanced liver cirrhosis $[10,11]$.

We aimed to assess the concentration of circulating NTproBNP in patients in various stages of liver cirrhosis and its value was correlated with the markers of cardiac dysfunction (mean arterial pressure, QT interval) and renal dysfunction (estimated glomerular filtration rate, GFR) and with markers of liver disease severity (Child-Pugh score).

\section{PATIENTS AND METHODS}

Eighty-eight patients diagnosed with liver cirrhosis on clinical, biochemical and morphological criteria were included in the study. They were divided into 3 groups. Group 1 included 18 patients $(20.5 \%)$ as controls, i.e. with compensated liver cirrhosis, without ascites. The group 2 included 35 nonazotemic cirrhotic patients (39.8\%) with ascites and creatinine values $<1.5 \mathrm{mg} / \mathrm{dl}$. In this group, 15 patients (42.8\%) had moderate ascites (2nd degree) and 20 patients (57.1\%) had massive ascites ( $3 \mathrm{rd}$ degree). Of these, 13 (37.1\%) were diagnosed with spontaneous bacterial peritonitis (SBP). Group 3 consisted of 35 patients (39.8\%) with liver cirrhosis and HRS: 17 patients (48.57\%) had type $1 \mathrm{HRS}$ and 18 patients $(51.42 \%)$, type 2 HRS. Twenty patients (57.1\%) of these had SBP.

No patient was on medication with betablockers, diuretics or albumin. They were enrolled in the study at the admission in the hospital, and blood samples were taken before any medication.

The HRS diagnosis was established based on the 2007 International Ascites Club criteria: cirrhosis with ascites; serum creatinine $>1.5 \mathrm{mg} / \mathrm{dl}$; no improvement of serum creatinine (decrease $\leq 1.5 \mathrm{mg} / \mathrm{dL}$ ) after volume expansion; absence of shock; no treatment with nephrotoxic drugs; absence of parenchymal kidney disease as indicated by proteinuria $>500$ $\mathrm{mg} /$ day, microhematuria (>50 RBCs/high power field), and/ or abnormal renal ultrasound scanning [12].

Excluded from our study were the patients with: liver cirrhosis and kidney failure of other etiology than HRS; cardiac disease (ischemic heart disease, arterial hypertension, valvulopathy etc.); clinically obvious heart failure; recent gastrointestinal bleeding with hemodynamic instability; thyroid dysfunction (hypo or hyperthyroidism) and patients under treatment with corticosteroids or conversion enzyme inhibitors.

The cardiac dysfunction was assessed in the studied patients using the following parameters:

- mean arterial pressure $\mathrm{MAP}=(\mathrm{SP}+2 \mathrm{DP}) / 3(\mathrm{SP}-$ systolic pressure, $\mathrm{DP}$ - diastolic pressure);

- corrected QT interval (Qt $)$, calculated using the following formula: $\mathrm{QT}_{c}(\mathrm{msec})=\mathrm{QT} /(\mathrm{RR})^{1 / 2}$, where $\mathrm{QT}-$ the measured QT interval, RR - the interval between two consecutive R-wave peaks. The result was divided by the predicted QT interval for the respective frequency $(\mathrm{x} \%)$. The normal value of the QTc ranges between $90 \%-110 \%$ of the predicted QT for the respective frequency. A prolonged $\mathrm{QT}_{\mathrm{c}}$ interval was defined when it exceeded $110 \%$ of the predicted QT interval for the respective heart frequency;

- NT-proBNP concentration (the N-terminal fragment of the prohormone B-type natriuretic peptide) was measured using the Biomedica bio-enzyme test provided by Biomedica Medizinprodukte GmbH\&CoKG (Wien, Austria). The method is based on a sandwich ELISA test. The normal value listed on the kit is $<350 \mathrm{fmol} / \mathrm{ml}$ (average $250-350 \mathrm{fmol} / \mathrm{ml}$ ).

The kidney function was assessed in the patients using the following parameters:

- serum creatinine;

- serum cystatin C. The "Quantikine Cystatin C" immunoenzymatic assay used in the measurement was provided by R\&D Systems, Inc, Minneapolis, USA. The assay employs a quantitative immunoenzymatic technique (sandwich ELISA). The normal serum cystatin C value is 792 $\pm 161 \mathrm{ng} / \mathrm{ml}$ (ranges $553-1257 \mathrm{ng} / \mathrm{ml}$ );

- creatinine clearance, estimated using the MDRD 6 equation; the calculator, available at the Internet address http://www.tinkershop.net/nephro.htm\#gfr_levey, includes 6 parameters (age, sex, race, serum creatinine, urea, albumin);

- estimated GFR from the serum cystatin C value, using the Hoek formula: eGFR $\left(\mathrm{ml} / \mathrm{min} / 1.73 \mathrm{~m}^{2}\right)=-4.32+80.35 /$ Cys C (mg/l) [13].

The patients' prognosis was assessed with the MELD score, calculated using bilirubin, INR and creatinine values of the patient (http://www.mayoclinic.org/meld/mayomodel5.htm).

\section{Statistical analysis}

Statistical analysis was performed with the SPSS 16.0 software for Windows, Medcalc 10.3.0.0 (Demo Versions). The $\chi 2$ test was used in order to analyse the differences between the qualitative variables. The normality of distribution of continuous numerical variables was assessed with the Kolmogorov-Smirnov test. The differences between the means of continuous quantitative variables were evaluated with the Student $t$ test, while for variables with non-normal distribution, non-parametric tests (Mann-Whitney U) were used. The ANOVA and Kruskal-Wallis tests were also used. A $p$ value $<0.05$ was considered statistically significant.

\section{RESULTS}

The clinical and demographic characteristics of the three patient groups are presented in Table I.

\section{NT-proBNP concentration}

The NT-proBNP values did not have a normal distribution and the results have been expressed as means. The highest mean value $(960 \mathrm{fmol} / \mathrm{ml}$ ) was found in HRS patients, significantly higher than that found in cirrhotic patients without ascites (435 $\mathrm{fmol} / \mathrm{ml})(\mathrm{p}<0.05)$ and also than that of non-azotemic cirrhotic patients with ascites $(660 \mathrm{fmol} / \mathrm{ml})(\mathrm{p}<0.05)$. Furthermore, the non-azotemic patients with ascites had significantly higher values than the cirrhotic patients in the control group $(\mathrm{p}<0.05)$ (Table II). This suggests that the cardiac dysfunction was already present in the non-azotemic cirrhotic patients with ascites. The most severe heart dysfunction was recorded in the group of patients with HRS.

The median NT-proBNP value was significantly increased in type $1 \mathrm{HRS}$ patients $(1080 \mathrm{fmol} / \mathrm{ml})$ as compared to type 2 HRS patients $(940 \mathrm{fmol} / \mathrm{ml})(\mathrm{p}=0.047)$. 
Table I. Clinical and demographic characteristics of the three patient groups.

\begin{tabular}{llll}
\hline & $\begin{array}{l}\text { Group 1 } \\
\mathrm{n}=18\end{array}$ & $\begin{array}{l}\text { Group 2 } \\
\mathrm{n}=35\end{array}$ & $\begin{array}{l}\text { Group 3 } \\
\mathrm{n}=35\end{array}$ \\
\hline $\begin{array}{l}\text { Age (mean } \pm \\
\text { SD, years) }\end{array}$ & $53.6 \pm 9.8$ & $55.1 \pm 10.1$ & $60.6 \pm 8.4$ \\
$\begin{array}{l}\text { Etiology } \\
\text { alcohol/viral } \\
\text { (n of patients) }\end{array}$ & $6 / 12$ & $20 / 15$ & $16 / 19$ \\
$\begin{array}{l}\text { Child (A/B/C) } \\
\text { (n of patients) }\end{array}$ & $16 / 2 / 0$ & $0 / 9 / 26$ & $0 / 4 / 31$ \\
$\begin{array}{l}\text { Child-Pugh } \\
\text { score (interval) }\end{array}$ & $5-6$ & $7-14$ & $8-15$ \\
$\begin{array}{l}\text { Ascites n (\%) } \\
\text { SBP n (\%) }\end{array}$ & - & $35(100 \%)$ & $35(100 \%)$ \\
$\begin{array}{l}\text { Encephalopathy } \\
\mathrm{n}(\%)\end{array}$ & - & $13(37.1 \%)$ & $20(57.1 \%)$ \\
\hline
\end{tabular}

The median NT-proBNP value found in patients who died from the entire study group was higher than the median value of all surviving patients $(1500 \mathrm{fmol} / \mathrm{ml}$ versus $660 \mathrm{fmol} / \mathrm{ml})$ $(\mathrm{p}=0.0025)$.

NT-proBNP concentration and etiology of liver cirrhosis

The HRS group was divided into two subgroups, according to liver disease etiology: 16 patients had alcoholic cirrhosis and 19 patients had viral cirrhosis. No significant differences of the NT-proBNP median values were found between the subgroups (1005 fmol/ml vs $960 \mathrm{fmol} / \mathrm{ml}$ ).

Two subgroups according to the etiology were also selected in patients with moderate or massive ascites: 20 patients with alcoholic cirrhosis and 15 patients with viral cirrhosis. No significant differences were recorded between these two subgroups, either $(660 \mathrm{fmol} / \mathrm{ml}$ vs $690 \mathrm{fmol} / \mathrm{ml})$.

\section{QT interval}

An electrocardiogram at the admission, simultaneously performed with the blood tests was available in 46 patients. The number of the patients from each group was almost similar: 14 patients of the controls (group 1), 17 patients of group 2, and 15 patients of group 3. The group 3 (HRS patients) had the highest median QTc interval value, at a statistically significant difference from the control group (460.53 msec vs $397.14 \mathrm{msec}$ ). In patients from group 2 the QTc interval was also significantly increased as compared to the controls (452.35 msec vs $397.14 \mathrm{msec}$ ) (Table II).

The proportion of patients with prolonged QTc interval was $35.7 \%$ in group $1,82.4 \%$ in group 2 and $100 \%$ in group 3 .

\section{Correlation of the parameters of cardiac dysfunction}

NT-proBNP, the QTc interval and the MAP were selected as parameters of cardiac dysfunction. The correlation of the proBNP concentration with the other parameters of cardiac dysfunction was assessed and the following significant correlations were found: between NT-proBNP and the QTc interval $(\mathrm{r}=0.540 ; \mathrm{p}<0.001)$, between proBNP and MAP $(\mathrm{r}=$ -0.377; $\mathrm{p}<0.001)$, between the QTc interval and MAP $(\mathrm{r}=$ $-0.404 ; \mathrm{p}=0.005)$.
Table II. Parameters of cardiac and renal dysfunction and prognostic factors in the three cirrhotic patient groups.

\begin{tabular}{|c|c|c|c|c|}
\hline \multirow[t]{2}{*}{ Parameter } & \multicolumn{3}{|c|}{ Group } & \multirow[t]{2}{*}{$\mathrm{p}$} \\
\hline & 1 & 2 & 3 & \\
\hline $\begin{array}{l}\text { NT-proBNP } \\
(\text { fmol/ml) } \\
\text { median value }\end{array}$ & 435 & 660 & 960 & $\begin{array}{l}\mathrm{p}^{*}<0.0001 \\
\mathrm{p}^{* *}<0.0001 \\
\mathrm{p}^{* * *}=0.0041\end{array}$ \\
\hline $\begin{array}{l}\mathrm{QTc}(\mathrm{msec}) \\
\text { median value }\end{array}$ & 397.14 & 452.35 & 460.53 & $\begin{array}{l}\mathrm{p}^{*}=0.0001 \\
\mathrm{p}^{* *}<0.0001 \\
\mathrm{p}^{* * *}=0.6641\end{array}$ \\
\hline $\begin{array}{l}\text { Proportion of } \\
\text { patients with } \\
\text { prolonged } \\
\text { QTc (\%) }\end{array}$ & 35.7 & 82.4 & 100 & $\begin{array}{l}\mathrm{p}^{*}=0.0019 \\
\mathrm{p}^{* *}<0.0001 \\
\mathrm{p}^{* * *}=0.137\end{array}$ \\
\hline $\begin{array}{l}\text { MELD score } \\
(\text { mean } \pm S D)\end{array}$ & $8.27 \pm 3.96$ & $18.08 \pm 5.89$ & $27.8 \pm 8.16$ & $\begin{array}{l}\mathrm{p}^{*}<0.0001 \\
\mathrm{p}^{* *}<0.0001 \\
\mathrm{p}^{* * *}<0.0001\end{array}$ \\
\hline $\begin{array}{l}\text { Cys } C(\mathrm{ng} / \mathrm{ml}) \\
\text { median value }\end{array}$ & 1462 & 1893 & 4293 & $\begin{array}{l}\mathrm{p}^{*}=0.0047 \\
\mathrm{p}^{* *}<0.0001 \\
\mathrm{p}^{* * *}<0.0001\end{array}$ \\
\hline $\begin{array}{l}\text { MDRD6 } \\
(\mathrm{ml} / \\
\left.\text { in/1.73m } \mathrm{m}^{2}\right)\end{array}$ & $75.25 \pm 13.45$ & $66.13 \pm 23.36$ & $19.62 \pm 8.92$ & $\begin{array}{l}\mathrm{p}^{*}=0.1332 \\
\mathrm{p}^{* *}<0.0001 \\
\mathrm{p}^{* * *}<0.0001\end{array}$ \\
\hline $\begin{array}{l}\text { Cys Cl Hoek } \\
(\mathrm{ml} / \\
\left.\mathrm{in} / 1.73 \mathrm{~m}^{2}\right)\end{array}$ & $53.33 \pm 15.68$ & $39.14 \pm 16.13$ & $18.83 \pm 9.16$ & $\begin{array}{l}\mathrm{p}^{\star}=0.0039 \\
\mathrm{p}^{\star *}=0.009 \\
\mathrm{p}^{\star * *}=0.002\end{array}$ \\
\hline
\end{tabular}

Group 1- cirrhotic patients without ascites; group 2 - non-azotemic cirrhotic patients with ascites; group 3 - cirrhotic patients with HRS;

$\mathrm{p}^{*}$ - comparison between groups 2 and $1 ; \mathrm{p}^{* *}$ - comparison between groups 3 and $1 ; \mathrm{p}^{* * *}$ - comparison between groups 3 and 2

The strongest correlation (Fig. 1) was recorded between the NT-proBNP level and the QTc interval.

\section{NT-proBNP concentration and liver disease severity}

The liver disease severity was assessed using the Child-Pugh score. The NT-proBNP concentration was significantly higher with each Child-Pugh point, correlating with the severity of the liver disease (Fig. 2) $(\mathrm{r}=0.501, \mathrm{p}<0.01)$.

\section{NT-proBNP concentration and markers of renal} dysfunction

The kidney function parameters (serum cystatin C, creatinine clearance estimated with the MDRD6 formula,

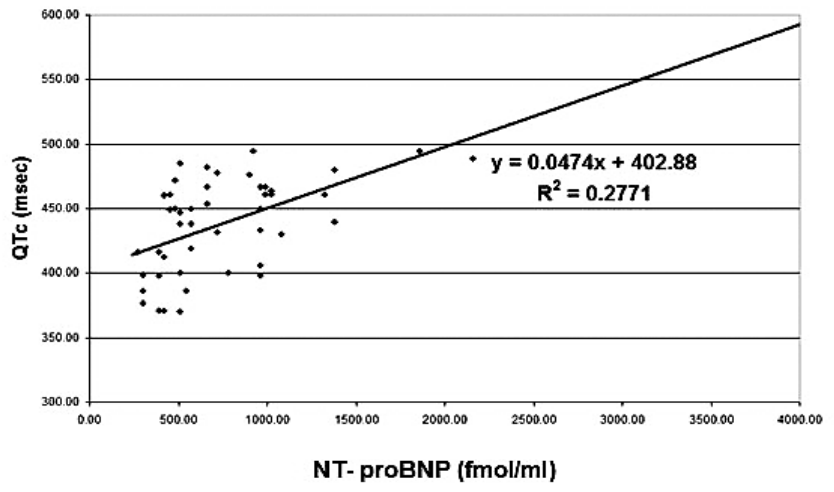

Fig. 1. Correlation between the NT-proBNP concentration and the QTc interval. $\mathrm{y}=\mathrm{QTc}$ interval $(\mathrm{msec}) ; \mathrm{x}=\mathrm{NT}-\mathrm{proBNP}(\mathrm{fmol} / \mathrm{ml})$ 


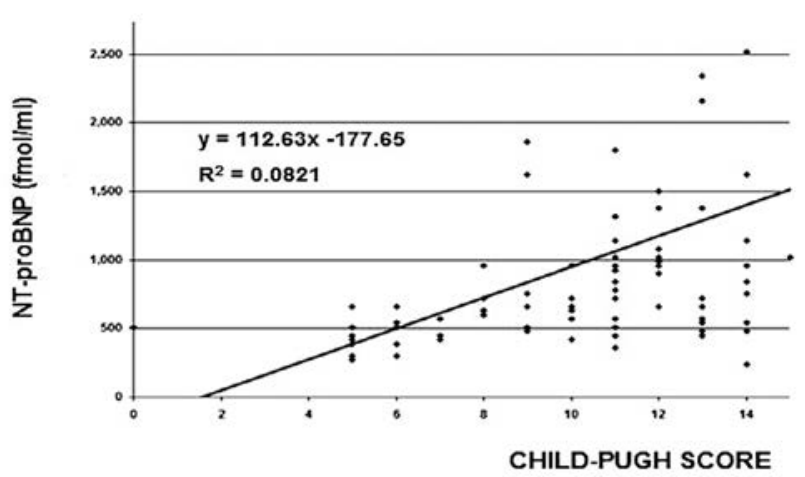

Fig. 2. Correlation between the NT-proBNP ( $\mathrm{fmol} / \mathrm{ml}$ ) concentration and the Child-Pugh score.

$\mathrm{y}=$ NT-proBNP $(\mathrm{fmol} / \mathrm{ml}) ; \mathrm{x}=$ Child-Pugh score

serum cystatin C clearance estimated with the Hoek formula) are displayed in Table II. When studying the correlation between the NT-proBNP concentration and the estimated GFR, a significant negative relationship was found $(r=-0.505$; $\mathrm{p}<0.01$ with the estimated creatinine clearance using the MDRD 6 equation, and $r=-0.575 ; \mathrm{p}<0.01$ with the estimated GFR using the Hoek formula derived from the serum cystatin C value).

Figure 3 presents the correlation between cardiac dysfunction (assessed by the NT-proBNP concentration) and renal dysfunction (estimated by the $\mathrm{Cys} \mathrm{Cl}-\mathrm{Hoek}$ ). The NT-proBNP levels increased (cardiac dysfunction worsening) when the estimated clearance decreased (renal dysfunction worsening).

\section{NT-proBNP concentration and prognosis}

The prognosis of the patients in the entire group was assessed using the MELD score (Table II). Figure 4 presents the correlation between NT-proBNP concentration and MELD score. The prognosis worsened as the NT-proBNP levels increased, indicating worsening of cardiac dysfunction.

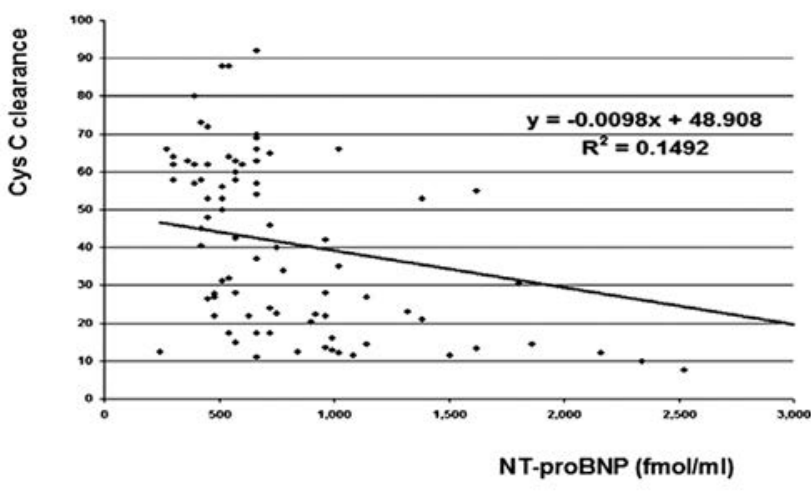

Fig. 3. Correlation between the NT-proBNP level and cystatin C clearance estimated with the Hoek formula $\mathrm{y}=$ Cys $\mathrm{C}$ clearance $\left(\mathrm{ml} / \mathrm{min} / 1.73 \mathrm{~m}^{2}\right) ; \mathrm{x}=\mathrm{NT}-\operatorname{proBNP}(\mathrm{fmol} / \mathrm{ml})$

\section{DISCUSSION}

The diagnosis of cirrhotic cardiomyopathy is established after exclusion of other cardiopathies (ischemic heart disease,

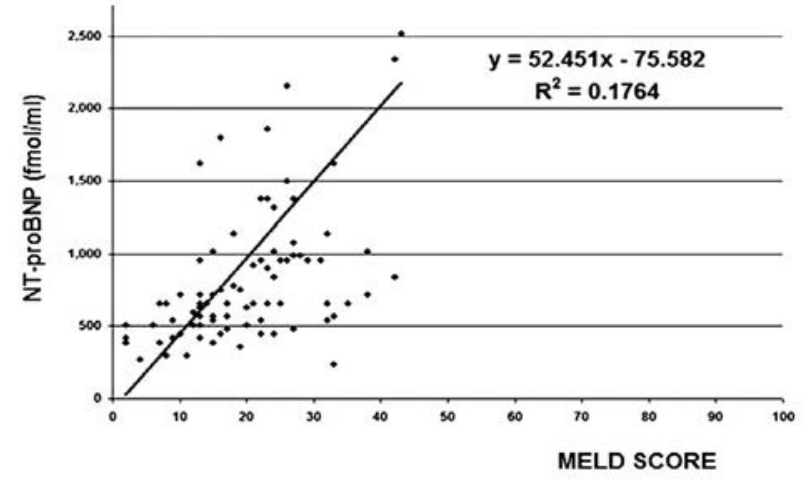

Fig. 4. Correlation between the NT-proBNP level and the MELD score.

$\mathrm{y}=\mathrm{NT}$-proBNP $(\mathrm{fmol} / \mathrm{ml}) ; \mathrm{x}=\mathrm{MELD}$ score

arterial hypertension, valvulopathies, congenital cardiopathies, alcoholic cardiomyopathy, hemochromatosis etc.) The diagnosis is difficult to establish in basal conditions (even with the dobutamine stress test), because cardiac function is normal at rest. The disease can be tolerated for a long time, because the ventricular underfilling due to splanchnic arterial vasodilation may mask the presence of ventricular failure. However, this is unmasked by physiologic or pharmacologic stress, bacterial infections (SBP) or after surgery (TIPS placement or liver transplantation) $[14,15]$.

BNP and proBNP levels reflect the presence of myocardial hypertrophy and cardiac dysfunction and are particularly useful in screening patients for cirrhotic cardiomyopathy. The $B N P$ gene is expressed predominantly on the myocytes of the insufficient left ventricle, leading to increased secretion of BNP to the circulation. The natriuretic peptides are synthesized as pre-prohormones with endocrinologically-active C-terminal peptides. The proteolytic cleavage of proBNP to N-terminal proBNP (1-76) and biologically-active C-terminal BNP takes place in the cardiomyocytes. The larger $\mathrm{N}$-terminal fragments of the proBNP are more stable and have a longer plasma halflife and thus a better detection profile as compared to the active C-terminal BNP hormone. ProBNP is a better indicator of cardiac dysfunction and its levels increase in symptomatic as well as asymptomatic latent heart failure $[16,17]$.

In cirrhotic patients, proBNP measurement may be impaired by its cleavage in smaller fragments and by alterations of its liver metabolism. The hepatic arteriovenous extraction of BNP and proBNP is not significantly different in cirrhotic patients as opposed to healthy controls; in cirrhotic patients, the circulating levels of proBNP and BNP reflect increased secretion in the cardiomyocytes, and not decreased hepatic uptake. The usual measurement methods of $\mathrm{N}$-terminal proBNP (NT-proBNP) use antibodies targeted against specific epitopes of the $\mathrm{N}$-terminal pro-peptide. These allow the measurement of both the intact $\mathrm{N}$-terminal fragments of proBNP (1-76) and the smaller N-terminal proBNP fragments (1-21), reflecting the total circulating proBNP concentration $[18,19]$.

In patients with advanced liver cirrhosis, an increased concentration of BNP and proBNP was reported, reflecting the cardiac dysfunction present in these patients. The proBNP levels are an even a better indicator of early cardiac dysfunction 
than BNP levels. The first study to report an increase in proBNP concentration in cirrhotic patients was published by Henriksen et al, who also reported the correlation between the serum levels of cardiac peptides with markers of liver disease severity, of cardiac and renal dysfunction $[19,20]$.

The patients with HRS have a decreased renal blood flow, GFR and sodium excretion, which appear to be correlated to the decrease in systolic function [21]. In our study, the NTproBNP levels in the HRS group were significantly higher than in the non-azotemic patients with ascites; the latter were also significantly higher than in the patients without ascites. These findings reveal the presence of a cardiac dysfunction not only in HRS patients, but also in non-azotemic patients with advanced liver cirrhosis and ascites. Seven out of the 8 patients with the highest NT-proBNP values (over $1500 \mathrm{fmol} / \mathrm{ml}$ ) had the lowest values of estimated GFR (cys C clearance under 30 $\mathrm{ml} / \mathrm{min} / 1.73 \mathrm{~m}^{2}$ ), and all of them had HRS.

In type 1 HRS patients, NT-proBNP levels were significantly higher than in type 2 HRS patients, supporting the claim that type 1 HRS patients have a more severe cardiac dysfunction.

The deceased patients had significantly higher NT-proBNP levels as compared with the surviving patients. All deceased patients were in advanced stages of liver cirrhosis $(88.8 \%$ were also diagnosed with HRS), and the onset of renal dysfunction and the poor prognosis of these patients were also linked to the systolic cardiac dysfunction.

The onset of cardiac dysfunction was not related to the alcoholic or viral etiology of the cirrhosis: no significant differences were found between the NT-proBNP levels in alcoholic as compared to viral cirrhosis, evaluated in the same stage of disease (non-azotemic cirrhosis with ascites and cirrhosis with HRS, respectively). These findings are concordant with those of other studies [20].

A prolonged QTc interval was found in over $50 \%$ of cirrhotic patients and was correlated with the grade of liver dysfunction. The life-threatening arrhythmias are rare in cirrhotic patients and the prolongation of the QT interval per $s e$ is not an indication for beta-blocker treatment [20,22, 23].

In our study, the median values of the QTc interval were significantly higher in the HRS group and in patients with ascites. A direct correlation of the serum NT-proBNP concentration with the QTc interval was found $(\mathrm{p}<0.001)$ and a negative correlation with the MAP values $(\mathrm{p}=0.005)$. The circulating NT-proBNP thus correlates with cardiac dysfunction, which is more severe in patients with advanced liver cirrhosis.

We must admit that the low number of patients with measured QTc interval might have influenced the significance of the correlations reported. NT-proBNP levels should have also been evaluated in correlation with other parameters of systolic and diastolic dysfunction.

A significant correlation of the serum NT-proBNP concentration with the Child-Pugh score was found, proving the link between cardiac dysfunction and liver disease severity. This finding is in agreement with the previous reports, which found a more frequent and more severe cardiac dysfunction in patients with advanced liver disease as compared to those with mild liver disease $[19,24]$.
The systolic cardiac dysfunction of patients with advanced liver cirrhosis is an important pathogenetic factor for renal dysfunction. The patients with liver cirrhosis having a cardiac output $<6 \mathrm{l} / \mathrm{min}$ and decreased MAP are at high risk of developing HRS. Maintaining cardiac contractility is essential in preventing renal dysfunction and HRS $[25,26]$.

The results of our study regarding the significant correlations between the NT-proBNP levels and the estimated GFR with the MDRD6 formula, cystatin C clearance with the Hoek formula are in agreement with the literature data and support the cardio-renal interrelation in patients with advanced liver cirrhosis. The correlation between the NT-proBNP concentration and the GFR proves that the cardiac dysfunction present in patients with advanced cirrhosis has an important pathogenic role in the development of HRS. The cardio-renal interrelation has clear therapeutic implications. Optimizing the cardiac output in patients with liver cirrhosis and ascites is an important step in HRS prophylaxis and treatment $[19,20,26]$.

The significant relationship between the NT-proBNP concentration and the MELD score found in our study stresses the prognostic value of cardiac dysfunction markers, which are correlated with patient survival. Similar to other reports, the lowest survival rate was found in patients with the most severe cardiac dysfunction. The decrease in cardiac output plays a part in the onset of the HRS and influences the poor prognosis of the patients with advanced cirrhosis [27].

\section{CONCLUSIONS}

The high NT-proBNP levels in our patients with advanced cirrhosis indicate the presence of cardiac dysfunction. The cardiac dysfunction was correlated with the liver disease severity. The correlation between the NT-proBNP concentration and the glomerular filtration rate argues in favour of the cardiorenal interrelation in patients with liver cirrhosis.

Conflicts of interest. No conflict to declare.

\section{REFERENCES}

1. Iwakiri Y, Groszmann RJ. The hyperdynamic circulation of chronic liver diseases: from the patient to the molecule. Hepatology 2006;43:121-131.

2. Møller S, Henriksen J. The systemic circulation in cirrhosis. In: Gines P, Arroyo V, Rodes J, Schrier R (eds). Ascites and renal dysfunction in liver disease. Pathogenesis, diagnosis and treatment. Massachusetts, Blackwell Publishing, 2005:139-155.

3. Møller S, Iversen JS, Henriksen JH, Bendtsen F. Reduced baroreflex sensitivity in alcoholic cirrhosis: relations to hemodynamics and humoral systems. Am J Physiol Heart Circ Physiol 2007; 292:H2966-H2972.

4. Møller S, Henriksen JH. Cirrhotic cardiomyopathy. J Hepatol 2010;53:179-190.

5. Zambruni A, Trevisani F, Caraceni P, Bernardi M. Cardiac electrophysiological abnormalities in patients with cirrhosis. J Hepatol 2006;44:994-1002.

6. Alqahtani SA, Fouad TR, Lee SS. Cirrhotic cardiomyopathy. Semin Liver Dis 2008;28:59-69. 
7. Møller S, Henriksen JH. Cardiovascular complications of cirrhosis. Gut 2008;57:268-278.

8. Ripoll C, Yotti R, Bermejo J, Bañares R. The heart in liver transplantation. J Hepatol 2011;54:810-822.

9. Sola E, Ginès P. Renal and circulatory dysfunction in cirrhosis: current management and future perspectives. J Hepatol 2010;53:1135-1145.

10. Møller S, Henriksen JH. Cardiovascular dysfunction in cirrhosis Pathophysiological evidence of a cirrhotic cardiomyopathy. Scand J Gastroenterol 2001;36:785-794.

11. Finucci G, Desideri A, Sacerdoti D, et al. Left ventricular diastolic function in liver cirrhosis. Scand J Gastroenterol 1996;31:279-284.

12. Salerno F, Gerbes A, Gines P, Wong F, Arroyo V. Diagnosis, prevention and treatment of hepatorenal syndrome in cirrhosis. Gut 2007;56:1310-1318.

13. Hoek FJ, Kemperman FA, Krediet RT. A comparison between cystatin C, plasma creatinine and the Crockcroft and Gault formula for the estimation of glomerular filtration. Nephrol Dial Transplant 2003;18:2024-2031.

14. Zardi E, Abbate A, Zardi DM, et al. Cirrhotic cardiomyopathy. J Am Coll Cardiol 2010;56:539-549.

15. Merli M, Valeriano V, Funaro S, et al. Modifications of cardiac function in cirrhotic patients treated with transjugular intrahepatic portosystemic shunt (TIPS). Am J Gastroenterol 2002;97:142-148.

16. Campell DJ, Mitchelhill KI, Schlicht SM, Booth RJ. Plasma aminoterminal pro-brain natriuretic peptide: a novel approach to the diagnosis of cardiac function. J Card Fail 2000;6:130-139.

17. Goetze J, Kastrup J. Plasma pro-brain natriuretic peptides are strong biochemical markers in clinical cardiology. Scand J Clin Lab Invest Suppl 2001;234:47-51.

18. Goetze JP, Kastrup J, Pedersen F, Rehfeld JF. Quantification of pro-Btype natriuretic peptide and its products in human plasma by use of an analysis independent of precursor processing. Clin Chem 2002;48:10351042.

19. Henriksen JH, Goetze JP, Fuglsang S, Christensen E, Bendtsen F, Møller S. Increased circulating pro-brain natriuretic peptide (proBNP) and brain natriuretic peptide (BNP) in patients with cirrhosis: relation to cardiovascular dysfunction and severity of disease. Gut 2003;52:1511 1517

20. Møller S, Henriksen JH. Cirrhotic cardiomyopathy: a pathophysiological review of circulatory dysfunction in liver disease. Heart 2002;87:9-15

21. Nazar A, Guevara M, Sitges M, et al. Left ventricular function assessed by echocardiography in cirrhosis: Relationship to systemic hemodynamics and renal dysfunction. J Hepatol 2013;58:51-57.

22. Ytting H, Henriksen JH, Fuglsang S, Bendtsen F, Møller S. Prolonged Q-Tc interval in mild portal hypertensive cirrhosis. J Hepatol 2005;43:637-644.

23. Bernardi M, Calandra S, Calantoni A, et al. Q-T interval prolongation in cirrhosis: prevalence, relationship with severity, and etiology of the disease and possible pathogenetic factors. Hepatology 1998;27:28-34.

24. Yildiz R, Yildirim B, Karincaoglu M, Harputluoglu M, Hilmioglu F. Brain natriuretic peptide and severity of disease in non-alcoholic cirrhotic patients. J Gastroenterol Hepatol 2005;20:1115-1120.

25. Ruiz-del-Arbol L, Monescillo A, Arocena C, et al. Circulatory function and hepatorenal syndrome in cirrhosis. Hepatology 2005;42:439-447.

26. Fierbinteanu-Braticevici C, Tribus L, Petrisor A, Usvat R, Bengus A. The hemodynamic impairment in cirrhotic patients with hepatorenal syndrome. J Hepatol 2011;54:S81.

27. Krag A, Bendtsen F, Henriksen JH, Møller S. Low cardiac output predicts development of hepatorenal syndrome and survival in patients with cirrhosis and ascites. Gut 2010;59:105-110. 